\title{
As (não) convocações de mulheres para cargos de liderança nas comissões técnicas no Handebol brasileiro nos anos de 2014-2020
}

\author{
Women's (no) calls for leadership offices in the technical \\ committees of the brazilian handball teams in 2014-2020
}

Convocatorias (no) de mujeres para oficinas de liderazgo en comités técnicos de balonmano brasileño en los años 2014-2020

\author{
iD (9) Leandro Amâncio Silva \\ Universidade Federal de Goiás, Goiânia, GO, Brasil. \\ e-mail: leandrooaa@gmail.com \\ iD (9) Juliana Fagundes Jacó \\ Universidade Estadual de Campinas, Campinas, São Paulo, Brasil \\ iD? Tathyane Krahenbühl \\ Universidade Federal de Goiás, Goiânia, GO, Brasil. \\ e-mail: tathy04n@gmail.com
}

\begin{abstract}
Resumo: O objetivo deste estudo foi quantificar as convocações de muIheres para os cargos de liderança nas comissões técnicas das seleções nacionais masculinas e femininas de handebol. Foram analisadas as convocações oficiais de 2014 a 2020 e verificadas quantas vezes homens e mulheres foram convocados para os cargos do estudo. Foram verificadas 58 convocações, sendo que, no feminino, tivemos 18 convocações para o cargo de supervisora, apenas uma convocação para auxiliar técnica e não houve convocação para treinadora principal. No masculino não houve convocação de mulheres para os cargos estudados. Concluímos que o cenário do handebol de alto nível brasileiro é predominantemente
\end{abstract}


comandado por homens, refletindo as desigualdades de gênero no campo profissional esportivo.

Palavras-chave: Gênero. Esporte. Mulher. Treinadora.

Abstract: The objective of the study was to verify how many women were summoned to leadership positions in the technical commissions of the national men's and women's handball teams. The official summons between the years 2014 and 2020 were analyzed and it was verified how many times men and women were summoned to the study positions. We have a total of 58 calls, there was no call for main coach, only one call for technical assistants and 18 calls for female supervisor. In men, there was no call for women for the positions studied. We conclude that the scenario of high-level Brazilian handball is predominantly led by men, reflecting gender inequalities in the professional sports field.

Keywords: Gender. Sport. Woman. Coach.

Resumen: El objetivo del estudio fue cuantificar la convocatoria de mujeres para puestos de liderazgo en las comisiones técnicas de los equipos nacionales de balonmano masculino y femenino. Se analizó la citación oficial entre los años 2014 y 2020 y se verificó cuántas veces fueron convocados hombres y mujeres a los puestos de estudio. Tenemos un total de 58 convocatorias, no hubo convocatoria de entrenador principal, solo una convocatoria de auxiliares técnicos y 18 convocatorias de supervisor, en el equipo femenino. En los hombres, no hubo convocatoria de mujeres para los puestos estudiados. Concluimos que el escenario del balonmano brasileño de alto nivel está liderado predominantemente por hombres, lo que refleja las desigualdades de género en el ámbito deportivo profesional.

Palabras clave: Género. Deporte. Mujer. Entrenador.

Submetido em: 21-09-2020

Aceito em: 28-01-2021 
As (não) convocações de mulheres para cargos de liderança nas comissões técnicas... Leandro Amâncio Silva • Juliana Fagundes Jacó • Tathyane Krahenbühl

\section{Introdução}

As mulheres têm conquistando cada vez mais espaço no campo esportivo, principalmente quando estão na posição de atletas, como visto nas últimas edições dos Jogos Olímpicos, em que as mulheres tiveram participação total de 40\% em Sidney em 2000 (PFISTER, 2003), e no Rio de Janeiro em 2016 o Brasil apresentou número recorde de participantes mulheres, sendo 209 de um total de 465 atletas (COB, 2016).

Apesar dessa crescente participação como atletas, as mulheres ainda são minoria em cargos de liderança e comando esportivo, tais como treinadoras esportivas e auxiliares técnicas (FERREIRA, SALLES; MOURÃO, 2015), sendo sub-representadas em todas as facetas de liderança em todos os níveis de esporte. Nos cargos de liderança nas instituições esportivas, as mulheres ainda têm uma representatividade muito pequena (ACOSTA; CARPENTER, 2012; BURTON, 2015; Walker, Bopp; SAGAS, 2011).

O Comitê Olímpico Internacional (COI) em 2020 chegou à marca de $47,7 \%$ de mulheres na composição de suas comissões, número este alcançado em razão do desenvolvimento de uma política de igualdade de gênero da instituição (COI, 2020). No âmbito nacional, em 2019 a estrutura do Comitê Olímpico Brasileiro (COB) contava com 128 mulheres e 108 homens, porém, mesmo sendo maioria em quantidade, a representatividade destas mulheres em cargos de liderança é de 43,5\% (COB, 2019). Assim, apesar de todos os avanços conquistados pelas mulheres nas práticas esportivas, temos que o esporte, enquanto prática cultural, ainda é um espaço de predomínio masculino, inclusive quando são observados os cargos de liderança.

No esporte, o corpo feminino e masculino são predominantemente marcados por discursos binários que naturalizam as diferenças entre os sexos e as pautam em aspectos médicos e biológicos que favorecem a inserção masculina e, ao mesmo tempo, dificultam a inserção feminina. Isso porque o esporte, como outras 
As (não) convocações de mulheres para cargos de liderança nas comissões técnicas... Leandro Amâncio Silva • Juliana Fagundes Jacó • Tathyane Krahenbühl

práticas sociais, circunscreve no corpo habilidades generificadas, ou seja, pautadas no gênero. O termo gênero aqui compreendido como "um elemento constitutivo de relações sociais baseadas nas diferenças percebidas entre os sexos, uma forma primária de dar significados às relações de poder" (SCOTT, 1995, p. 86). Isto é, tal conceito se refere ao modo como as características sexuais são compreendidas e representadas e, ainda, hierarquizam as relações sociais. Conforme afirma Haraway, "gênero é um conceito desenvolvido para contestar a naturalização da diferença sexual em múltiplos terrenos de luta" (HARAWAY, 1995, p. 221).

De acordo com Lauretis (1994), a construção do gênero ocorre por meio de várias "tecnologias de gênero" e discursos institucionais com poder de controlar o campo da significação social que implantam representações de gênero, tornando os corpos em homens e mulheres, assim as representações de gênero vão dando inteligibilidade aos indivíduos. Concebe-se aqui uma lógica que nos situa que há uma construção do sujeito feminino: "Ainda que as formas de conceber os processos de construção possam ser (e efetivamente são) distintas, lidar com o conceito de gênero significa colocar-se contra a naturalização do feminino e, obviamente, do masculino" (LOURO, 2007, p. 207).

No campo esportivo diversas "tecnologias" atuam ao longo do tempo na construção de um sujeito feminino, por exemplo, discursos médicos e legais do início do século XX que consideravam as mulheres biologicamente inaptas para o esporte e socialmente destinadas à maternidade e aos cuidados com o lar (GIGLIO et al., 2018). Com isso, por muito tempo às mulheres cabia o papel de assistir o desempenho atlético dos homens ou, quando autorizadas, poderiam praticar exercícios calistênicos, considerados condizentes com a sua condição (PFISTER, 2003), que estava associada à fragilidade dos órgãos reprodutores e à delicadeza física, por exemplo.

Seguindo essa construção cultural de dominância e ausência dos direitos das mulheres, no Brasil, o Decreto-Lei n ${ }^{\circ}$ 3.199, de 14 de abril de 1941, que vigorou até a década de 1970, proibia que 
As (não) convocações de mulheres para cargos de liderança nas comissões técnicas... Leandro Amâncio Silva • Juliana Fagundes Jacó • Tathyane Krahenbühl

mulheres praticassem vários esportes como lutas, futebol, rúgbi, polo, polo aquático, entre outros. Nesse período, o handebol ainda era pouco praticado no país e restrito a São Paulo, sendo disseminado apenas a partir da década de 1960, contudo, como a maioria dos esportes considerados viris, foi influenciado pelas circunstâncias desse decreto. Apesar do decreto supracitado não ser específico para outras funções esportivas, como treinadoras e auxiliares técnicos, contribuiu significativamente para a afirmação do esporte como território hegemonicamente masculino (Ferreira et al., 2017).

No entanto, os discursos sobre a inaptidão das mulheres para a prática esportiva vêm perdendo força (FERREIRA et al., 2013), vemos o crescente aumento quantitativo de mulheres no esporte ao longo do século XX e XXI. Devide (2005) demonstra que ao longo do tempo o esporte se transformou, rupturas e descontinuidades na sua trajetória permitiram expandir o horizonte de práticas corporais femininas e masculinas. Por isso, mesmo havendo a hegemonia do masculino, o esporte não é estático e absoluto, sendo espaço possível para resistências.

As mulheres ganharam espaço também como treinadoras esportivas ao longo dos anos, mas os cargos de liderança esportiva relacionados com a comissão técnica ainda são majoritariamente ocupados por homens, sendo que essa diferença torna-se cada vez maior quanto mais se aproxima do alto rendimento (PFISTER, 2003).

Em um estudo envolvendo a Liga Brasileira de Basquete feminino, entre os anos de 2010 a 2017, observou-se que o número de mulheres treinadoras manteve-se estável ocupando $24 \%$ do total de cargos, contudo, nesse período, houve diminuição de $88 \%$ para 34\% na participação de mulheres como assistentes técnicas (PASSERO et al., 2019). No futebol brasileiro, esporte culturalmente masculino, mesmo quando em equipes femininas, ao fazer a distribuição de gênero por cargo da comissão técnica, observa-se que nos Campeonatos Brasileiros de Futebol Feminino entre 2013 a 2019 , apenas $17 \%$ dos cargos de treinador e $22 \%$ dos cargos de 
As (não) convocações de mulheres para cargos de liderança nas comissões técnicas... Leandro Amâncio Silva • Juliana Fagundes Jacó • Tathyane Krahenbühl

auxiliar técnico foram ocupados por mulheres (PASSERO et al., 2020).

Esses estudos mostram que existe uma predominância masculina nos cargos de comando. Assim, vemos que os cargos de treinador principal e auxiliar/assistente são os que ainda apresentam grande desequilíbrio de gênero (PASSERO et al., 2020). Corroborando essa ideia, Walker e Bopp (2010) apontam que as mulheres representam $42,6 \%$ dos técnicos nos esportes femininos, enquanto que nos esportes masculinos elas representam menos de $3 \%$ dos treinadores principais.

Dessa forma, com o aumento das equipes e atletas femininas observado nos últimos anos, principalmente nos grandes eventos esportivos, esperava-se também observar o aumento do espaço para a atuação de mulheres como treinadoras esportivas. Contudo, os estudos mostram que essa razão é inversamente proporcional, como visto após o Title IX, à medida que os esportes femininos ganharam espaço e aumentaram significativamente nos Estados Unidos, os homens passaram a demonstrar maior interesse em atuar nessas modalidades (KILTY, 2006; ACOSTA; CARPENTER, 2012; PASSERO et al., 2020).

Diante desse cenário, levantamos as questões: no handebol brasileiro, em que a seleção nacional feminina tem maior destaque pelo seu título mundial em 2013 e por sua potência nas Américas, como se encontra quantitativamente o número de mulheres em cargos de liderança em comissões técnicas, tanto feminina quanto masculina, nas seleções nacionais? Temos uma reprodução dos padrões encontrados em outras modalidades esportivas ou há uma maior inserção de mulheres nos quadros de liderança?

Visto isso, o objetivo do estudo foi verificar a quantidade de mulheres que ocupam cargos de liderança, tais como: Supervisora, Treinadora principal, Auxiliar Técnica e Assistente Técnica nas comissões técnicas das seleções adultas e olímpicas, masculinas e femininas do handebol brasileiro e, a partir desses dados, dialogar com outras publicações a fim de refletir sobre esse cenário esportivo. 
As (não) convocações de mulheres para cargos de liderança nas comissões técnicas... Leandro Amâncio Silva • Juliana Fagundes Jacó • Tathyane Krahenbühl

\section{Metodologia}

A pesquisa se deu a partir das análises das convocações de atletas e comissões técnicas, das seleções adultas e olímpicas, masculinas e femininas publicadas no site da Confederação Brasileira de Handebol ${ }^{1}$ (CBHb), a partir do ano de 2014 até julho do presente ano (2020). A escolha desse período é devido aos arquivos estarem disponíveis a partir desta data no site oficial da confederação.

Coletamos os nomes dos profissionais que ocupavam os seguintes cargos da comissão técnica: supervisor(a), treinador(a) ou técnico(a) principal, assistente técnico(a) ou auxiliar técnico(a), e contabilizamos a quantidade de vezes em que mulheres ocuparam esses cargos. Foram determinadas se as pessoas inscritas nesses cargos nas súmulas são homens ou mulheres a partir do primeiro nome e verificadas a partir de redes sociais e conhecimento pessoal dos pesquisadores.

A pesquisa assume papel quantitativo e característica documental, pois analisa a quantidade de vezes que os dados são fornecidos nos documentos pesquisados. Assim, a pesquisa quantitativa é focada na mensuração de fenômenos, envolvendo a coleta e análise de dados numéricos (COLLIS; HUSSEY, 2005). Além de ser elaborada a partir de materiais que não receberam tratamento analítico, ou seja, documentos oficiais de primeira mão (GIL, 2006). Todos os dados foram tabulados em planilha Microsoft Excel ${ }^{\circledR}$ e foram realizadas as distribuições de frequência absoluta e relativa (porcentual).

\section{Resultado}

A partir da análise do período de 2014 a 2020, encontramos o total de 58 (100\%) convocações de comissões técnicas e identificamos que 28 (48,3\%) foram para as seleções adulta ou olímpica

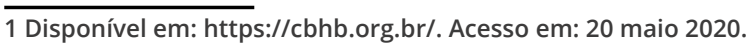


As (não) convocações de mulheres para cargos de liderança nas comissões técnicas... Leandro Amâncio Silva • Juliana Fagundes Jacó • Tathyane Krahenbühl

masculina e 30 (51,7\%) foram para as seleções adulta ou olímpica feminina, como mostra a tabela 1:

Tabela 1. Total de convocações das Seleções Brasileiras de Handebol durante o período de 2014 a 2020.

\begin{tabular}{|c|c|c|}
\hline Ano & Seleção Feminina & Seleção Masculina \\
\hline 2014 & 7 & 9 \\
\hline 2015 & 7 & 5 \\
\hline 2016 & 4 & 5 \\
\hline 2017 & 4 & 2 \\
\hline 2018 & 4 & 4 \\
\hline 2019 & 3 & 2 \\
\hline 2020 & 1 & 1 \\
\hline Total & 30 & 28 \\
\hline
\end{tabular}

Fonte: elaborado pelos autores a partir dos dados encontrados no site da CBHb. Disponivel em: https://cbhb.org.br/v1/site/institucional.

Quando analisados os cargos em questão das seleções femininas, em 30 convocações observou-se que as mulheres foram convocadas 1 (uma) única vez como segunda auxiliar técnica, representando $1,05 \%$ do total das convocações e 18 vezes como supervisoras. Destaca-se que das 18 convocações para o cargo de supervisão, 17 foram para a mesma pessoa. Nas seleções masculinas não tivemos convocações de mulheres para os cargos analisados no período do estudo. Esses dados são demonstrados a seguir na tabela 2: 
As (não) convocações de mulheres para cargos de liderança nas comissões técnicas... Leandro Amâncio Silva • Juliana Fagundes Jacó • Tathyane Krahenbühl

Tabela 2. Total de convocações de mulheres para os cargos analisados nas Seleções Brasileiras de Handebol no período de 2014 a 2020.

\begin{tabular}{|c|c|c|c|c|}
\hline & \multicolumn{2}{|c|}{$\begin{array}{c}\text { Convocações para seleções } \\
\text { femininas }\end{array}$} & \multicolumn{2}{c|}{$\begin{array}{c}\text { Convocações para seleções } \\
\text { masculinas }\end{array}$} \\
\hline & $\begin{array}{c}\text { Convocações } \\
\text { de mulheres }\end{array}$ & $\begin{array}{c}\text { Total de } \\
\text { convocações }\end{array}$ & $\begin{array}{c}\text { Convocações de } \\
\text { mulheres }\end{array}$ & $\begin{array}{c}\text { Total de } \\
\text { convocações }\end{array}$ \\
\hline Supervisor(a) & $18(18,94 \%)$ & 30 & $00(0 \%)$ & 28 \\
\hline Técnico(a) & $00(0 \%)$ & 30 & $00(0 \%)$ & 28 \\
\hline $\begin{array}{c}\text { Auxiliar } \\
\text { Técnico(a) }\end{array}$ & $00(0 \%)$ & 30 & $00(0 \%)$ & 28 \\
\hline $\begin{array}{c}\mathbf{2}^{\circ} \text { Auxiliar } \\
\text { Técnico(a) }\end{array}$ & $01(1,05 \%)$ & 05 & $00(0 \%)$ & 01 \\
\hline Total & $19(20 \%)$ & $95(100 \%)$ & $00(0 \%)$ & $85(100 \%)$ \\
\hline
\end{tabular}

Fonte: elaborado pelos autores a partir dos dados encontrados no site da CBHb. Disponivel em: https://cbhb.org.br/v1/site/institucional.

Dessa forma, identificamos que das convocações para cargos analisados nas comissões técnicas das seleções adultas e olímpicas, masculinas e femininas no período de 2014 a 2020, apenas $20 \%$ foram destinadas a mulheres. Ainda assim, 17 convocações foram para a mesma profissional, sendo a última em 2016, e após isso não tiveram mulheres em qualquer um dos cargos estudados nas comissões técnicas em ambos os naipes.

Ao analisar individualmente os cargos do estudo, temos que as 18 convocações para o cargo de supervisora de seleção representam um total de $60 \%$, quando considerada apenas a seleção feminina. Contudo, não foram convocadas mulheres no período estudado para os cargos de treinador principal e "primeiro" auxiliar técnico nessas seleções. Quando convocou um segundo auxiliar técnico, temos que em 05 (cinco) vezes que isso aconteceu, apenas 1 (uma) convocação foi destinada a uma mulher, representando $20 \%$ das convocações neste cargo em específico. No caso de considerar todas as convocações para o cargo de auxiliar técnico nas seleções femininas, independente de ter uma ou duas pessoas na mesma convocação para este cargo, esse percentual cai para $2,85 \%$. 
As (não) convocações de mulheres para cargos de liderança nas comissões técnicas... Leandro Amâncio Silva • Juliana Fagundes Jacó • Tathyane Krahenbühl

\section{Discussão}

Os resultados deste estudo mostram como o handebol de alto nível brasileiro tem predominância masculina nos cargos de comando das comissões técnicas na atualidade. Ao analisar as convocações das seleções nacionais, tanto feminina quanto masculina, foi possível perceber que são raras as ocasiões em que dirigentes da Confederação Brasileira de Handebol anunciam mulheres em suas comissões técnicas, portanto, há uma reprodução de um padrão observado em outras modalidades esportivas.

Nesse sentido, vemos que no esporte e especificamente no cenário do handebol brasileiro há uma acentuada assimetria na participação de homens e mulheres nos cargos de liderança das equipes nacionais. Esses achados corroboram os dados de Chimot (2004), que identificou que as mulheres correspondem apenas a 18,8\% dos cargos de treinadores nacionais na França e, no Reino Unido, esse número é de apenas $4 \%$ do total de técnicos das equipes nacionais femininas (NORMAN, 2008). Observa-se que, apesar da crescente inserção das mulheres no campo esportivo (principalmente como atletas) e o crescente destaque feminino no handebol brasileiro, não vemos o mesmo acontecer - na mesma proporção - nos cargos de comissão técnica da modalidade.

A crescente inserção feminina como atleta é muito importante em diversos aspectos, um deles é que essas mulheres rompem as fronteiras do que estava estabelecido como feminino, pois praticam esportes, se destacam e demonstram habilidades que muitas vezes estavam entendidas como tipicamente masculinas, ou seja, as mulheres passam a ocupar espaços que eram socialmente compreendidos como dos homens. Como afirmado na publicação da ONU intitulada "Mulheres, igualdade de gênero e os esportes" de 2007, que apontou a importância do esporte como possibilidade de desafiar os estereótipos e a discriminação de gênero, constituindo-se em um potente promotor da igualdade, autonomia e empoderamento feminino. 
As (não) convocações de mulheres para cargos de liderança nas comissões técnicas... Leandro Amâncio Silva • Juliana Fagundes Jacó • Tathyane Krahenbühl

No entanto, ao atravessar as fronteiras previamente estabelecidas, os corpos são recolocados nos atributos que lhes dão integibilidade e são modificados, o que gera novas e assimétricas relações de poder (BRAH, 2006). A forma como os cargos de liderança no handebol brasileiro estão sendo ocupados por homens e mulheres pode ser compreendida como uma das possíveis manifestações dessas novas e assimétricas configurações de relações de poder. Isto é, a ocupação de mulheres em determinadas áreas esportivas vai reconfigurando as relações em todo o cenário esportivo, mas ainda de forma que os homens ocupem espaços de maior protagonismo, controle e tomada de decisão.

Tal distribuição assimétrica dos espaços de liderança pode ser visto também em estudo realizado em Portugal, no qual Jaeger et al. (2010), ao entrevistarem 21 mulheres envolvidas com o ambiente esportivo do país, e algumas tendo longa história no esporte nacional, verificaram que nenhuma delas ocupou posição de comando no alto escalão do esporte português. Destas, apenas duas assumiram posições de dirigente, sendo uma como presidente de um clube exclusivo para mulheres e a outra como vice-dirigente em clube misto de basquetebol.

Portanto, temos uma realidade em que é rara a presença de mulheres no topo da hierarquia profissional no campo esportivo, o que também foi observado no handebol brasileiro através dos dados numéricos obtidos nesta pesquisa. Tal fenômeno, que não é exclusivo do esporte, vem sendo designado como "teto de vidro", que é um termo já consagrado nos estudos de gênero que, através de uma metáfora, tenta explicar as barreiras invisíveis e artificiais que impedem as mulheres de alcançar os postos mais elevados na hierarquia de trabalho.

Nesse sentido, estudos apontam a baixa representatividade de mulheres como treinadoras em clubes e equipes esportivas em razão dessas barreiras que diminuem as oportunidades de inserção e permanência no esporte (FERREIRA, SALLES; MOURÃO, 2015), que podemos compreender aqui como sendo o "teto de vidro". De acordo com a literatura, essas barreiras são determi- 
As (não) convocações de mulheres para cargos de liderança nas comissões técnicas... Leandro Amâncio Silva • Juliana Fagundes Jacó • Tathyane Krahenbühl

nantes para a não progressão das mulheres a cargos de liderança esportiva, principalmente no alto nível (PFISTER, 2003; FERREIRA, SALLES; MOURÃO, 2015; FERREIRA et al., 2017).

Entre as barreiras comumente encontradas por mulheres para desempenharem papéis de líderes no esporte estão: a dificuldade em relacionar família e trabalho, necessidade maior de provar a sua capacidade e competência, investimento financeiro baixo em estrutura, mídia e preparo de mulheres para assumirem esses cargos, salários desiguais entre homens e mulheres, o que por consequência causa desestímulo e necessidade de outras ocupações para se sustentarem, não podendo ter dedicação total ao esporte, falta de conhecimento dos motivos da desigualdade de gênero no esporte por parte de gestores e colegas, falta de pessoas que se disponham a auxiliar neste processo e a reprodução homóloga que tende a manter o clube dos homens dentro dos meios esportivos (KILTY, 2006; JAEGER et al., 2010; WALKER; BOPP, 2010; BURTON, 2015; FERREIRA et al., 2017; NOVAIS, MOURÃO; SOARES, 2017).

Somandas a essas situações estão a apropriação majoritária do espaço por homens, a falta de oportunidades de inserção, o preconceito, o conflito entre a vida pessoal e profissional e a baixa remuneração (FERREIRA et al., 2013; FERREIRA et al., 2017). Essas barreiras vão se estabelecendo como rearranjos de uma estrutura na qual as relações de poder no campo esportivo favorecem a inserção masculina.

Nessa perspectiva de compreensão das barreiras encontradas por mulheres, Norman (2010) descreve que uma das dificuldades que as mulheres encontram em assumir posições de comando no meio esportivo está ancorada em seu baixo capital social, que é relacionado à rede de contatos, mesmo quando apresentam capital humano significativo, ou seja, qualidade em experiências, em formação e em treinamento acumulados em busca da qualificação profissional.

Nessa mesma perspectiva, Ferreira et al. (2015) apontam que para ter acesso a cargos de técnico existe uma rede de influencia- 
As (não) convocações de mulheres para cargos de liderança nas comissões técnicas... Leandro Amâncio Silva • Juliana Fagundes Jacó • Tathyane Krahenbühl

dores, que podem ser chamados de tutores, que são responsáveis por contratar, indicar ou facilitar o acesso a cargos de comissão esportiva. Geralmente, esses cargos de influenciadores são compostos por homens que têm a tendência a indicarem outros homens e nem mesmo cogitarem mulheres que tenham as mesmas competências que os homens indicados, assim as indicações são realizadas pelo que os autores chamam de princípio da similaridade ou contratação homóloga.

Para compreender o impacto dessas redes de influenciadores nas contratações e convocações esportivas, é importante considerar que além da presença hegemônica como treinadores, também há dominância masculina nos cargos de dirigentes de federações, confederações e instituições esportivas (FERREIRA et al., 2017). O estudo de Ferreira et al. (2015) identificou que apenas $14 \%$ do efetivo dos principais órgãos esportivos do Brasil são de mulheres, e que apenas $7 \%$ das federações esportivas têm uma presidente mulher. Em relação à $\mathrm{CBHb}$, somente homens fizeram parte da presidência da instituição desde a sua fundação até a data atual². Das dificuldades e barreiras encontradas pelas mulheres para a inserção e permanência no esporte, a contratação homóloga e o princípio da similaridade parecem estar presentes também quando se trata de convocações para seleções nacionais, criando uma rede intransigente na qual as mulheres que conseguiram acesso a essas posições de comando não conseguem influenciar de modo a facilitar o acesso de outras mulheres, uma vez que ainda ocupam poucos espaços nessas redes de influenciadores.

Cunningham e Sagas (2002), Jaeger et al. (2010), Passero et al. (2019), Norman (2010) e Ferreira et al. (2017) mostram que as muIheres veem o cargo, desejam alcançar os objetivos profissionais, se preparam para a oportunidade, mas o caminho é dificultado por uma estrutura social que acaba fazendo com que se acostumem e se acomodem nos cargos inferiores ou de menor expressão e, por

\footnotetext{
2 Desde a fundação, a CBHb teve na sua presidência três homens: Prof. Jamil André de São Paulo, o alagoano Prof. José Maria Teixeira e o atual presidente Prof. Manoel Luiz Oliveira. Disponível em: https://cbhb.org.br/v1/site/institucional. Acesso em: 31 ago. 2020.
} 
As (não) convocações de mulheres para cargos de liderança nas comissões técnicas... Leandro Amâncio Silva • Juliana Fagundes Jacó • Tathyane Krahenbühl

vezes, sendo hierarquicamente abaixo dos cargos ocupados por homens.

Apesar dessas dificuldades, no mercado de trabalho de forma geral são vistas melhoras nas desigualdades de gênero, assim como vemos avanços na inserção de mulheres no campo esportivo. No entanto, no mercado de trabalho brasileiro, as mulheres ainda recebem, em média, $76 \%$ do rendimento dos homens. Além disso, as mulheres ocupam menos os cargos de direção e gerências (IBGE, 2017).

Sendo assim, tanto o mundo do esporte quanto o mercado profissional mundial de trabalho estão marcados por uma segregação vertical e horizontal que varia de acordo com o sexo (PFISTER, 2003), evidenciando aqui que as desigualdades de gênero no campo das atividades físicas e esportivas fazem parte de um amplo contexto de desigualdades presentes em outras esferas sociais (ALTMANN, 2017).

O mercado de trabalho na área esportiva e especificamente nos cargos por este estudo pesquisados, do handebol de alto nível, seguem os mesmos padrões que a sociedade em geral, tendo preferência por homens nestes cargos que demandam liderança. Nosso estudo corrobora essas afirmativas ao mostrar que uma mesma mulher foi convocada para a supervisão das equipes por 17 vezes no total de 58 convocações e, ainda assim, não foi concebido espaço para mulher no cargo de técnica. Percebendo, assim, o que Norman (2010) chama de "desempenhar o papel de treinadora complacente" e Ferreira et al. (2017) denomina de "conquistas difusas no campo esportivo", entendendo que, enquanto a alternativa para as mulheres for se adequar ou se encaixar a este espaço entranhado de relações de poder, as lutas individuais que demonstram resistência dessas mulheres que conseguiram chegar a posições de comando não irão alterar a estrutura hegemônica masculina, que futuramente outras mulheres terão que superar por elas mesmas.

Outro dado interessante é que, além de vermos mulheres em uma variedade muito pequena de cargos na comissão técnica do 
As (não) convocações de mulheres para cargos de liderança nas comissões técnicas... Leandro Amâncio Silva • Juliana Fagundes Jacó • Tathyane Krahenbühl

handebol brasileiro, o cargo mais vezes ocupado por uma mulher é o de supervisão. Esse dado chama a atenção, pois nele há, sobretudo, a função administrativa de organização de agendas, passaportes, logística dos atletas, ou seja, quase que os cuidados diários com a rotina mais ampla das equipes; não é uma atribuição que requer o uso de saberes técnicos e táticos do handebol ou do campo esportivo, como outras funções da comissão. É comum essa compreensão de que as mulheres seriam mais organizadas, detalhistas, observadoras do que os homens. Apesar de ser uma compreensão comum, não deixa de ser um entendimento estereotipado sobre os gêneros, assim como a compreensão de que as mulheres seriam menos hábeis nos quesitos técnicos-táticos esportivos, não firmes o suficiente para lidarem com situações de pressão ou de tomadas de decisão.

Walker, Bopp e Saga (2011) realizaram uma pesquisa com estudantes de administração esportiva e identificaram que o sexo influenciaria nas recomendações de contratação, na percepção de adequação ao trabalho e na capacidade de mulheres assumirem cargos de treinadoras do basquetebol universitário masculino, mostrando que mesmo que as mulheres sejam tão capazes e adaptáveis como os homens, existe a incongruência de gênero de que elas não seriam contratadas por não terem características culturalmente tidas como masculinas.

A divisão de ocupações pautadas em compreensões estereotipadas e limitadoras sobre as habilidades femininas foi também vista no contexto brasileiro no estudo de Ferreira et al. (2015), no qual identificou-se que grande parte das treinadoras limitam-se a trabalhar com as categorias de base e escolinhas de iniciação esportiva. Isso remete a uma estrutura socialmente posta de que as mulheres possuem capacidade para o ensino, principalmente com crianças, enquanto que os homens são capazes de liderar equipes de alto nível. Corroborando esta ideia, Reade, Rodgers e Norman (2009) identificaram que as proporções de mulheres e homens como treinadores são semelhantes a nível competitivo mais baixo, porém a presença feminina vai declinando à medida que se apro- 
As (não) convocações de mulheres para cargos de liderança nas comissões técnicas... Leandro Amâncio Silva • Juliana Fagundes Jacó • Tathyane Krahenbühl

xima do alto rendimento. Souza de Oliveira (2004) aponta que no Rio de Janeiro, apesar de contar com centenas de técnicos atuando nos nove principais clubes do estado, apenas 34 são mulheres, sendo que $64,5 \%$ delas atuam nas categorias de base.

Este artigo trouxe dados que apresentam o contexto do handebol brasileiro, e que, aparentemente, está normalizado: o baixo número de mulheres em comissões técnicas de seleções nacionais. Contudo, ressaltamos que há uma limitação ao analisar apenas os números e entendemos a necessidade de compreender os motivos pelos quais há predominância masculina nesses cargos com uma pesquisa mais ampla a partir de dados qualitativos. Entretanto, é relevante expor o cenário contemporâneo, que mesmo diante de um atual e crescente discurso de equidade e de empoderamento feminino na nossa sociedade, na prática, os espaços e locais de liderança ainda são ocupados majoritariamente (ou exclusivamente, como no masculino) por homens.

\section{Conclusão}

A partir dos dados analisados neste estudo, concluímos que poucas mulheres foram convocadas para cargos considerados de liderança nas comissões técnicas das seleções brasileira de handebol feminino e nenhuma no naipe masculino nos últimos anos. Nosso estudo não fez a análise qualitativa para saber quais as razões para que as mulheres não fossem convocadas para assumirem cargos nas seleções brasileiras de handebol, mas numericamente podemos observar que ainda há predominância dos homens nestes cargos, refletindo as desigualdades de gênero no campo profissional esportivo, mesmo em uma era marcada por lutas e conquistas das mulheres por direitos nos campos pessoal e profissional.

Para ampliar a presença de mulheres nos cargos de liderança esportiva é importante compreender que existem várias possíveis causas que interferem e influenciam os esportes a não inserirem 
As (não) convocações de mulheres para cargos de liderança nas comissões técnicas... Leandro Amâncio Silva • Juliana Fagundes Jacó • Tathyane Krahenbühl

as mulheres em posições de comando dentro das instituições. Compreendendo que a ascensão profissional das mulheres na carreira esportiva é dificultada por fatores sociais, acarretando uma baixa quantidade de treinadoras e auxiliares atuando no alto nível, e consequentemente diminuindo significativamente as possibilidades de convocações em seleções nacionais, vemos que esse quadro se mantém no handebol brasileiro, uma vez que a Confederação Brasileira de Handebol (CBHb) não proporcionou nos últimos 6 (seis) anos oportunidades significantes para mulheres em posições de liderança nas seleções brasileiras masculinas e femininas.

Essa ocupação de cargos de liderança é importante para incluir as mulheres nas redes de influenciadoras, possibilitando que mulheres competentes sejam indicadas e ocupem esses cargos, o que gera representatividade, rompe com fronteiras e oportuniza a ampliação de acesso de diferentes pessoas ao campo esportivo.

\section{Referências}

ACOSTA, R.V; CARPENTER, L.J. Women in Intercollegiate Sport: A Longitudinal, National Study. Thirty-Five Year Update, 19772012. Acosta-Carpenter, 2012.

ALTMANN, H. Atividades físicas e esportivas e mulheres no Brasil. Relatório nacional de desenvolvimento humano no Brasil. 2017. Disponível em: http://movimentoevida.org/wp-content/ uploads/2017/09/Atividades-Fi\%CC\%81sicas-e-Esportivas-eGe\%CC\%82nero.pdf. Acesso: 11 set. 2020.

BRAH, A. Diferença, diversidade, diferenciação. Cadernos Pagu, n. 26, p. 329-376, 2006.

BRASIL. Decreto Lei $n^{\circ} 3199$, de 14 de abril de 1941. Estabelece as bases de organização dos desportos em todo o país. Diário Oficial da União 16 abr.1941; p. 7453. https://www2.camara.leg.br/legin/ fed/declei/1940-1949/decreto-lei-3199-14-abril-1941-413238-publicacaooriginal-1-pe.html Acesso em: 21 Ago. 2020. 
As (não) convocações de mulheres para cargos de liderança nas comissões técnicas... Leandro Amâncio Silva • Juliana Fagundes Jacó • Tathyane Krahenbühl

BURTON, L.J. Underrepresentation of women in sport leadership: A review of research. Sport management review, v. 18, n. 2, p. 155-165, 2015.

CHIMOT, C. Répartition sexuée des dirigeant (e) s au sein des organisations sportives françaises. Staps, n. 4, p. 161-177, 2004.

COLLIS, J; HUSSEY, R. Pesquisa em administração: um guia prático para alunos de graduação e pós-graduação. Bookman, 2005.

Comitê Olímpico Brasileiro (COB). Curiosidades Olímpicas. 2016. Disponível em: https://www.cob.org.br/pt/cob/time-brasil/brasil-nos-jogos/curiosidades-olimpicas Acesso em: 21 Ago. 2020.

Comitê Olímpico Brasileiro (COB). Lenda Olímpica Aída dos Santos participa de debate sobre mulheres no esporte no COB. 2019. Disponível em: https://www.cob.org.br/pt/galerias/noticias/ lenda-olimpica-aida-dos-santos-participa-de-debate-sobre-mulheres-no-esporte-no-cob/. Acesso em: 13 jul. 2020.

Comitê olímpico internacional (COI). Women and girls must be participants and leaders in sport recovery plans, says un women. 2020. Disponível em: https://www.olympic.org/news/women-and-girls-must-be-participants-and-leaders-in-sport-recovery-plans-says-un-women. Acesso em: 13 jul. 2020.

CUNNINGHAM, G.B; SAGAS, M. The differential effects of human capital for male and female Division I basketball coaches. Research Quarterly for Exercise and Sport, v. 73, n. 4, p. 489-495, 2002.

DEVIDE, F.P. Gênero e mulher no esporte: história das mulheres nos jogos olímpicos moderno. ljuí: Unijuí, 2005.

FERREIRA, H.j; Salles, J.G.C; Mourão, L; Moreno, A. A baixa representatividade de mulheres como técnicas esportivas no Brasil. Movimento, v. 19, n. 3, p. 103-124, 2013.

FERREIRA, H.J; SALLES, J.C.G; MOURÃO, L.N. Inserção e permanência de mulheres como treinadoras esportivas no Brasil. Journal of Physical Education, v. 26, n. 1, p. 21-29, 2015. 
As (não) convocações de mulheres para cargos de liderança nas comissões técnicas... Leandro Amâncio Silva • Juliana Fagundes Jacó • Tathyane Krahenbühl

FERREIRA, H.j; dos ANJOS, L. A; DRIGO, A.J; MOURÃO, L.N; do CARMO SALLES, J.G. Barriers faced by Brazilian female coaches. Revista Brasileira de Educação Física e Esporte, v. 31, n. 2, p. 479-488, 2017.

GIGLIO, S.S; Galatti, L.R; Machado, G.V; Altmann, H; Paes, R.R; Seone, A.M. Desafios e percalços da inserção da mulher nos Jogos Olímpicos (1894-1965). Recorde: Revista de História do Esporte, v. 11, n. 1, 2018.

GIL, A.C. Métodos e técnicas de pesquisa social. 5. ed. São Paulo: Atlas, 2006.

HARAWAY, D. Ciencia, cyborgs y mujeres. La reinvención de la naturaleza. Manuel Talens. Valencia: Madrid: Ediciones Catedra, 1995.

IBGE. Síntese de indicadores sociais: uma análise das condições de vida da população brasileira. Estudos e pesquisas Informação demográfica e socioeconômica, n. 36, ISSN 1516-3296. Rio de Janeiro: IBGE/Coordenação de População e Indicadores Sociais, 2016a, 146 p. Disponível em: https://biblioteca.ibge.gov.br/ visualizacao/livros/liv98965.pdf Acesso em: 11 set. 2020.

JAEGER, A.; Gomes, P.B; Silva, P; Goellner, S.V. Trajetórias de mulheres no esporte em Portugal: assimetrias, resistências e possibilidades. Movimento, v. 16, n. 1, p. 245-267, 2010.

KILTY, K. Women in coaching. The sport psychologist, v. 20, n. 2, p. 222-234, 2006.

LAURETIS, T. "Tecnologias de Gênero". In: Hollanda, H. B. de. Tendências e impasses. O feminismo como crítica da cultura. Rio de Janeiro: Rocco, 1994.

LOURO, G.L. Gênero, sexualidade e educação: das afinidades políticas às tensões teórico-metodológicas. Educação em Revista, $n$. 46, p. 201-218, 2007.

NORMAN, L. The UK coaching system is failing women coaches. International Journal of Sports Science \& Coaching, v. 3, n. 4, p. 447-476, 2008. 
As (não) convocações de mulheres para cargos de liderança nas comissões técnicas... Leandro Amâncio Silva • Juliana Fagundes Jacó • Tathyane Krahenbühl

NORMAN, L. Bearing the burden of doubt: Female coaches' experiences of gender relations. Research quarterly for exercise and sport, v. 81, n. 4, p. 506-517, 2010.

NOVAIS, M.C.B; MOURÃO, L.N; SOARES, J.P.F. A dona da bola: questões de gênero na trajetória de uma treinadora de futebol. Seminário Internacional Fazendo Gênero 11 \& 13th Women's Worlds Congress (Anais Eletrônicos), Florianópolis, 2017. Disponível em:http://www.en.wwc2017. eventos.dype.com.br/resources/anais/1499426042_ARQUIVO_ TextoFinalFG2017MarianaNovais.pdf Acesso em: 31 ago. 2020. ORGANIZAÇÃO DAS NAÇÕES UNIDAS (ONU). Mulheres, igualdade de gênero e os esportes. Nova York, 2007.

PASSERO, J. G.; Barreira, J; Junior, A.C; Galatti, L.R. Gender (In) equality: A Longitudinal Analysis of Women's Participation in Coaching and Referee Positions in the Brazilian Women's Basketball League (2010-2017). Cuadernos de Psicología del Deporte, v. 19, n. 1, p. 252-261, 2019.

PASSERO, J.G; Barreira, J; Tamashiro, L; Scaglia, A.J; Galatti, L.R. Futebol de mulheres liderado por homens: uma análise longitudinal dos cargos de comissão técnica e arbitragem. Movimento (ESEFID/UFRGS), v. 26, p. 26060, 2020. PFISTER, G. Líderes femininas em organizações esportivas-Tendências mundiais. Movimento, v. 9, n. 2, p. 11-35, 2003.

READE, I; RODGERS, W; NORMAN, L. The under-representation of women in coaching: A comparison of male and female Canadian coaches at low and high levels of coaching. International Journal of Sports Science \& Coaching, v. 4, n. 4, p. 505-520, 2009. SCOTT, J. Gênero: uma categoria útil de análise histórica. Educação \& realidade, v. 20, n. 2, 1995.

SOUZA DE OLIVEIRA, G.A. Mulheres enfrentando o desafio da inserção, ascensão e permanência no comando de equipes esportivas de alto nível. In: SIMÕES, A.C; KNIJNIK, J.D. (Org.). 0 mundo 
As (não) convocações de mulheres para cargos de liderança nas comissões técnicas... Leandro Amâncio Silva • Juliana Fagundes Jacó • Tathyane Krahenbühl

psicossocial da mulher no esporte: comportamento, gênero, desempenho. São Paulo: Aleph, p. 319-335, 2004.

WALKER, N.A; BOPP, T. The underrepresentation of women in the male-dominated sport workplace: Perspectives of female coaches. Journal of Workplace Rights, v. 15, n. 1, 2011.

WALKER, N.A; BOPP, T; SAGAS, M. Gender bias in the perception of women as collegiate men's basketball coaches. Journal for the Study of Sports and Athletes in Education, v. 5, n. 2, p. 157-176, 2011.

\section{Publisher}

Universidade Federal de Goiás. Faculdade de Educação Física e Dança. Publicação no Portal de Periódicos UFG. As ideias expressadas neste artigo são de responsabilidade de seus autores, não representando, necessariamente, a opinião dos editores ou da universidade. 